\title{
ARTICLE
}

\section{A Transformational Conception of Evolutionary Processes*}

\author{
Nuno MARTINS \\ Lecturer at the Faculty of Economics and Management of the Portuguese Catholic University, \\ Faculdade de Economia e Gestão, Universidade Católica Portuguesa, Rua Diogo Botelho, \\ 1327, 4169-005 Porto, Portugal. E-mail: nmartins@porto.ucp.pt
}

\begin{abstract}
The transformational conception of social activity provides a non-deterministic framework within which evolutionary models of natural selection can be located, and constitutes an alternative to sociological and economic traditions that adopt a deterministic conception of social processes, in which the causal effects of social structures, or technology, for example, are conceptualized in a deterministic way. Natural selection processes can be conceptualized as a more specific instance of this broad (non-deterministic) transformational conception, and hence can provide additional insight whenever addressing cases where a more specific model is required.
\end{abstract}

Keywords: transformational conception of social activity, evolutionary processes, economic methodology, technology, social structures.

\section{Introduction}

Economic history studies the joint effects of several structures, such as institutional, geographical or technological structures, in a concrete spatio-temporal scenario. In particular, it analyses the total effects of the complex interrelationship between these structures in the production, distribution, accumulation and consumption of goods and services. However, while the analysis economic historians undertake provides insight as to how social and technological structures co-produce events in a given period of time, usually it does not give us a model of the transformation of social structures and technology through time. And when a model of socio-economic transformation is provided, such a model often consists in a deterministic account of socio-economic change, in which it is assumed that a particular structure (such as the mode of

JEL: B41, B52, N01.

*For most helpful comments on an earlier draft I am most thankful to Liliana Fernandes, John Latsis and two anonymous referees. I also benefited much from discussions on the topic of this paper with Tony Lawson. 
production, or technology, or social structures) determines, or drives, history.

An advantage of deterministic approaches to economic history is the simplicity of the theory provided. In fact, in a deterministic theory, the problems involved in the identification of the relative strength of each causal structure are solved by assuming that one particular structure (be it technology, social structures, or the mode of production, for example) overrules all the others. But such a deterministic conception leads to the neglect of the effects of structures other than the one that is assumed to determine events.

In order to provide a model that takes into account the role of different causal structures on economic change I will suggest an evolutionary approach to institutional and technological change, which can be seen as part of a broader transformational conception. I shall start by describing a general transformational conception that explains the reproduction and transformation of social and technological structures in section 2 . In section 3 an evolutionary model formulated by Tony Lawson will be suggested as a more specific account of socio-economic change. In section 4 I shall discuss Makoto Nishibe's interpretation of Tony Lawson's position, and argue that natural selection models can fruitfully complement the transformational conception of social activity, by providing a more concrete specification of a broad transformational process. In section 5 I shall address the possibility of Lamarckian processes as particular cases, which occur when socio-technological structures shape human capacities and dispositions. In section 6 I will identify specific social rules that can act as social replicators in the evolutionary model suggested. In section 7 some illustrations will be provided, of how the evolutionary model suggested in this paper can provide a more satisfactory account of socio-technological transformation than deterministic models. In section 8 the evolutionary model presented will be used to analyze the transformation of economic agents and their epistemological conceptions. Some concluding remarks will be made afterwards, in section 9 .

\section{A Transformational Conception of Institutions, Technology, Human Agents and Resources}

Social structures and technology constitute the conditions of possibility for the human activities of production, distribution, consumption and accumulation of material resources, which are ultimately supported by biological structures. Biological structures are usually taken to be stable in economic analysis (changes in the total stock of natural resources are taken into account, but changes in the biological structures and processes through which natural resources are generated and transformed are not considered), 
because throughout the world history biological structures changed at a significantly lower pace than social and technological structures (albeit it can be argued that economic activity has been causing significant changes in the natural realm in the last two centuries). So although biological structures are entities in continuous transformation, the analysis of economic change has been mostly concerned with structures that change at a faster pace, like social structures and technology.

In a conception where material resources, human agents, social structures and technology are seen as entities in a process of continuous transformation, a key question concerns the causal relations between these entities. In many sociological and economic traditions, processes primarily related to one of the entities named above have been considered as the sole determinant or causal force of human activity, with the complex interactions between these processes being neglected, by assuming that one of them overrules all the others.

Thus, perspectives like neoclassical economics often neglect the causal role of social structures, by assuming social reality to be the outcome of the atomistic interaction of human agents who permanently optimize an objective function that describes their goals. In neoclassical economics, the human agent's preferences (together with the existing constraints to the exercise of such preferences, such as endowments and technology) are assumed to be the ultimate cause of events-and social norms, when taken into account, are interpreted as the outcome of the strategic interaction of optimizing agents.

On the other hand, some sociological traditions (often identified with the work of ...Emile Durkheim) follow the opposite route, and assume that human agency is determined by social structures (by the existing rules, conventions and norms). Other authors consider technology to be the ultimate cause of events, a position often labeled as "technological determinism"- - for a useful discussion of this position, see Heilbroner (1967), Smith and Marx (1996), or Clive Lawson (2007)—while some Marxian authors often place the economic activity of production of material resources as the ultimate determinant of history.

The problem with models that omit the causal role of social structures or technology is that they fail to take into account that economic activity takes place under conditions which are not chosen by human agents, but rather provided by an historically and geographically situated socio-technological configuration, which shapes the conditions for future activity. Conversely, the difficulty with models that assume human agency to be completely determined either by social structures, technology or the mode of production of material resources is that, in those models, human agents are relegated to 
the role of passive subjects that are entirely shaped by underlying forces.

However, human beings are essentially active creatures, and not passive subjects, as Veblen $(1897,1898 \mathrm{a})$ notes. To be sure, social, technical and productive activity all contribute to the formation of habits and routines, and so have some effect on the capabilities, propensities and dispositions of human agents. But unless we neglect the causal powers of human agents as creative and active beings, we cannot presuppose that human dispositions and propensities are entirely shaped either by social structures, technology or a given mode of production. This issue will be further clarified in section 5.

A conception of material resources, human agents, social structures and technology in which these are seen as entities in a process of continuous transformation provides the ground for an account of economic activity where all these entities can play a causal role in economic growth and development, and the greater causal power of one of these entities can be conceptualized as a particular case within a broader transformational perspective.

There are already transformational conceptions of entities like social structures, technology, human agents and material resources in the literature, which contain the central insights of the perspective sketched here. In a series of contributions to the economic literature under the heading of critical realism in economics - on which see, for example, Lawson (1997, 2003a)—a transformational conception of social structures and human agency has been proposed, where social structures and human agency are argued to be ontologically distinct entities. By "ontology" it is meant an inquiry into the nature of social reality. Hence, to say that social structures are ontologically distinct from human agency means that both social structures and human agency are a constitutive part of social reality (of social being), and that even though social structures and human agency are interdependent, they are different modes of social being, irreducible to each other.

The social structure can be seen as emergent from the interaction of human agents. Lawson (1997: 63) defines 'emergence' as "a relationship between two features or aspects such that one arises out of the other and yet, while perhaps being capable of reacting back to it, remains causally and taxonomically irreducible to it".

Hence, the social structure in which human agents are positioned is ontologically distinct from the human agent who slots into it, and from her or his own subjectivity. So social structures are a condition of possibility of human agency. However, human agents, as ontologically distinct and active entities, may not just reproduce social structures in 
their daily practices, but also modify them. Social structures facilitate or constrain human agency, by providing a set of possibilities, but do not determine, nor are determined by, human agents.

Clive Lawson (2007) has recently made an important contribution to the transformational conception of social reality, by suggesting a transformational conception of technology. Lawson argues that in a similar way to the one in which social structures are continuously reproduced or transformed through human agency, so are technical objects continuously reproduced and transformed by technical subjects (that is, by human agents). Technical objects are the condition of possibility of human agency (in particular, technical activity), but are ontologically distinct from human agents.

Of course, the human agents themselves will also be transformed through social activity and technical activity. For while some dispositions and instincts were shaped through biological evolution, and hence are, to a great extent, biologically innate, other habits and propensities will be acquired through experience and interaction with the social environment (that is, during a process of socio-economic evolution).

So social structures, technology and human agents can all be seen as ontologically distinct entities that are continuously reproduced and transformed through socioeconomic evolution. Social structures (including institutions and organizations), technological structures, and economic production, are set into motion by human dispositions (propensities, habits and instincts) to engage in intentional human agency, wherein the reproduction and transformation of social and technological structures shapes the conditions under which the human activities of production, distribution, exchange, consumption and accumulation of material resources will take place.

Several authors who are seen as forerunners of an evolutionary approach to economics adopt a conception of social processes similar to the transformational conception. Alfred Marshall, for example, believed that, throughout an historical process, social institutions will continuously transform the character of individuals, while at the same time individuals will transform the social institutions with which they interact. Marshall distinguishes between the mechanical operations of the human brain, and a nonmechanical self-consciousness, through the action of which both social institutions, and the mechanical dispositions in the brain which form the person's character, are continuously transformed—see Rafaelli (1991).

The action of individuals in order to transform social institutions is seen by Marshall as an exercise of what G. W. F. Hegel (1824a, b) calls their 'subjective freedom', while the social institutions which are thus transformed according to human reason will be 
identified with what Hegel (1824a, b) calls 'objective freedom'-see Whitaker (1975), and Cook (2009) for a discussion. In this sense, the human agent has an ability to transform underlying social structures, which constrain and facilitate human activity for Marshall too. However, as Cook (2009) notes, Marshall stresses the role of mechanical dispositions in character and reason, and the influence of economic life and industrial organization in character and reason, to a greater extent than Hegel did. But just like Marshall does not believe the human individual to be completely shaped by institutions or technology, nor does he believe that reason acts unconstrained by industrial context or social institutions.

In fact, it is not only Marshall (1890), but also other key authors of evolutionary approaches to economics, like Veblen (1898a) and Schumpeter (1942), that seem to adopt an ontology very similar to the transformational conception of critical realism. Of course, Veblen was more concerned with the impact of social institutions and technology on human agents (and on their habits of thought), while Schumpeter emphasized the role of reasoning, creativity, and innovation, stressing the ability of human agents to transform technology and institutions. But Schumpeter, much inspired by Marx, places a great emphasis in the role of social conditions on human activity too, and Veblen criticizes the Marxist materialist interpretation of history precisely for overemphasising the role of social laws:

"The materialist theory conceives of man as exclusively a social being, who counts in a process solely as a medium of the transmission and expression of social laws and changes; whereas he is, in fact, also an individual, acting out his own life as such.” (Veblen, 1897: 137, cited in Lawson, 2003a)

In fact, an analysis of the works of Marshall, Veblen and Schumpeter has led many to find similarities with critical realism—see Pratten (1998) for an analysis of the work of Marshall from a critical realist perspective; Tony Lawson (2003a, b, 2005) for a study of work of Veblen from a realist perspective; and Mário da Graça Moura (2002) for an interpretation of the work of Schumpeter also from a critical realist perspective. Furthermore, Collier (1989) argues that even Marx can be interpreted under a transformational conception too, contrarily to the usual interpretations made in deterministic approaches to Marxism.

Now, the broad transformational conception summarized above gives us a general outline of how social rules, ideas, habits, technology and individuals are transformed and 
modified. Effectively, the fact that the transformational conception has been argued to underpin the work of such different authors as Marx, Marshall, Veblen and Schumpeter is a consequence of such a broad scope. But in order to undertake an analysis of concrete historical processes, a more specific model is required, in order to explain the reproduction and transformation of social institutions and technology. Without going into a further level of specificity, it is not possible to identify the mechanisms through which social institutions, technology and human agents causally affect each other. This issue will be addressed in the next section.

\section{An Evolutionary Specification of Social Processes}

Evolution can be characterized as a process of descent with modification, where descent can be taken to mean that entities are reproduced, and modification can be interpreted as signifying that the entities reproduced can be transformed throughout this process. Under this light, evolutionary processes can be broadly characterized as transformational processes_or 'unfolding sequences', to use Veblen's (1898a) expression—of cumulative change. Applied to economics, an evolutionary perspective would conceptualize material resources, human agents, social structures and technology as entities in a process of continuous transformation, wherein the outcome of every modification or transformation shapes the conditions under which further reproduction (descent) and transformation (modification) can take place.

However, evolution as a process of descent with modification still constitutes too broad a model to provide a more concrete analysis of social change. An example of more specific evolutionary models is given by natural selection models, which assume not only a process of descent with modification, but also the existence of more concrete mechanisms. In order to offer a more specific model of socio-economic change, I will now describe a model of natural selection proposed by Tony Lawson (2003a), the Population-Variety-Reproduction-Selection (PVRS) model, which systematizes the key aspects of Charles Darwin's (1859) model of natural selection.

Five essential elements to Lawson's PVRS model are the existence of a given population, variety, reproduction, selection, and some degree of independence between variety generating mechanisms and selection mechanisms-for a discussion, see Lawson (2003a: 121-123). A central distinction (which was not introduced in the literature by Darwin himself) is also required at this stage, namely the distinction between interactors and replicators. Interactors are the entities that compete in the environment of selection (see Hull, 1981), while replicators are the entities that pass on its structure (i.e., are 
reproduced) in the evolutionary process (see Dawkins, 1976, 1978).

After this distinction is made, we can combine it with the five essential elements of the PVRS model mentioned above, and differentiate three mechanisms: a variety-generating mechanism that generates different sorts of replicators; a replication mechanism, which transmits each replicator from an interactor to another; and a selection mechanism through which the population of interactors is selected in the environment.

Now, which social entities should we specify as the social interactors and the social replicators? Lawson argues that social practices are the most promising feature of the social realm to be used as a social interactor, and chooses social rules as the social replicators which are selected (or not) through the competition of social interactors. Lawson (2003a: 37) also notes that a social rule can be seen as a "code, convention, or understanding about how an act could or should be performed", where such code can be tacitly or consciously followed.

The replicators or social rules can then be taken in a broad sense, including also ideas, techniques and any type of codified information, which provide an underlying social form which is materialized (i.e., actualized) in social practices. For the essential feature of replicators in evolutionary models is that they contain a code that is transmitted through the replication mechanism. Such codes or information will often be combined with a physical or technological basis. Social rules, conventions, ideas and techniques can be materialized in books, artifacts or any means of recording codified information.

Replication mechanisms will be any mechanism that (while acting relatively independently from the environment of selection) contributes to the reproduction of a given rule, technique or code, while variety-generating mechanisms will be any mechanism that (again, while acting relatively independently from the environment of selection) creates new rules, techniques and codes. Human dispositions and propensities, for example, will be important sources of variation or replication. Competition between social practices will take place as social rules, techniques and codes become actualized in social practices, which constitute the environment of selection.

Now, a question one could ask is whether another social interactor could have been chosen instead of social practices. Nelson and Winter (1982), for example, choose organizations as the social interactors. And like organizations, so can human individuals be selected in an evolutionary social process. The same can happen to a geographical region (which does not physically disappear, but can lose economic, social, technological or demographic characteristics, or even see its biological and natural qualities disappear).

But note that Lawson's formulation can still encompass a situation where it is an 
individual, organization or region that is selected. For there are two ways in which the selection environment - the population of competing social practices-can lead to the selection of social practices in Lawson's formulation. The first, which will be termed here as direct selection of social practices, is by causing (or even forcing) individuals, organizations or regions to keep or to change their social practices (or at least influencing them to do so). In this case, social practices are selected directly through the decisions of individuals, organizations or regions (in the latter case, with decisions being made by the regional community) that choose to keep or abandon given social practices.

The second type of selection, to be termed here as indirect selection of social practices, consists in selecting or excluding those individuals, organizations or regions who engage in given social practices (for it may well be the case that people, organizations or regions decide to maintain given social rules, ideas or techniques regardless of how favored they may be by the environment of social practices). In this second case, social practices are selected indirectly through the selection of the individuals, organizations or regions that reproduce them. In both cases, the replicated code or information is selected through the competition of social interactors (viz., social practices), but only in the latter case human individuals, organizations or regions are also themselves selected.

Veblen (1899) also refers to a similar distinction between these two types of selection, by differentiating selection of stable types (that could be seen here as indirect selection of the stable replicators of an individual, organization or region) on the one hand, and selection as an adaptation of the agent's habits of thought (including the direct selection that individuals, organizations and regions make of their codes and rules of behavior and action) on the other hand. Nevertheless, Veblen is especially concerned with the evolution of replicators (of codes, social rules and techniques), and not the particular selection mechanism through which evolution occurs, or which specification of social interactors provides a better analogy. Thus he writes:

"For the present purpose, however, the question as to the nature of the adaptive process-whether it is chiefly a selection between stable types of temperament and character, or chiefly an adaptation of men's habits of thought to changing circumstances - is of less importance than the fact that, by one method or another, institutions change and develop. Institutions must change with changing circumstances, since they are of the nature of an habitual method of responding to the stimuli which these changing circumstances afford. The development of these 
institutions is the development of society." (Veblen, 1899: 118)

Lawson's specification of social practices as interactions solves many difficulties involved in the use of the biological analogy, such as those noted by Nelson (2006, 2007). If human individuals, organizations or regions were taken to be the interactors, we would have to assume a stable relationship between individuals, organizations or regions on the one hand, and rules (i.e., replicators) on the other hand-in order to avoid the epistemological difficulties that would spring from the possibility that interactors may change their replicators at any time, a possibility which would make it difficult to separate evolutionary causation from other causal factors. The choice of social practices as the interactors enables Lawson's PVRS model to obtain a stable correspondence between replicators and interactors, while allowing for the possibility that human agents, organizations and regions change their rules and practices.

Also, because the social interactor is social practices, the term "direct selection" is a better term than "adaptation" for the case when agents (for example individuals or organizations) change social practices, since changes in social practices in the PVRS model signify a selection of the interactor (which is precisely social practices), and not an adaptation of the interactor (adaptation would be an appropriate term for this case only if the individual or organization which changes social practices were taken to be an interactor).

\section{Level of Abstraction and Biological Analogies}

It is important to note that Lawson suggests caution when using biological analogies in natural selection models. In fact, Lawson (2003a) notes that while the transformational model of social activity was developed through an analysis of the social realm, natural selection models have been mostly concerned with finding analogies between the biological realm and the social realm. Lawson argues that models derived through an analysis of the biological realm will be appropriate in the social realm only in the particular cases when the social realm and biological realm display analogous mechanisms at play.

Makoto Nishibe (2006: 19-20) argues that, according to Lawson, evolutionary analysis cannot provide any additional insight to the transformational conception of social activity Lawson endorses. According to Nishibe (2006: 19), Lawson "concludes that borrowing evolutionary concepts or models of natural selection from biology into economics is of some use, but not more useful than TMSA [Transformational Model of 
Social Activity]". Nishibe then argues that evolutionary analysis can bring additional insight to the study of social processes. I believe Nishibe is right in arguing that evolutionary analysis can be most useful in social analysis, and can bring additional insights. However, I also believe this is Lawson's position too.

Part of the reason for this apparent disagreement is that Lawson and Nishibe are focusing on different levels of abstraction. Lawson (2003a: 112) defines evolution as a process of descent with modification, or cumulative causation, and within this more general process, identifies the Population-Variety-Reproduction-Selection (PVRS) model as a more specific evolutionary model, inspired in the biological process of natural selection. Lawson is critical of the universal use of natural selection models (which are only a particular type of evolutionary models) in the social realm, but does not criticize the broad characterization of social processes as evolutionary processes, if by the latter it is meant only a general process of descent with modification, or cumulative causation.

As Nishibe (2006: 18) notes, the work of economists like "Mandeville, Smith and Malthus contributed to the birth of the Darwin's theory of evolution", where evolution is seen as a process of descent with modification. Hence, the general characterization of evolution as descent with modification, or cumulative causation, was much inspired by authors who developed their thinking through an analysis of the social realm.

However, Lawson warns that more specific evolutionary models inspired in subsequent developments in biology, such as natural selection models, may not always be appropriate, since it cannot be guaranteed a priori that the analogies between the biological and the social realm presupposed in those more specific models will hold universally.

Hence, as Nishibe (2006: 19) notes, Lawson focuses on a more narrow conception of evolutionary economics in his critique, such as the natural selection type of models, although Lawson's conception of evolution does not reduce the latter to natural selection. In fact, as Lawson stresses, neither did Darwin, for in the final edition of The Origin of Species, Darwin (1872) makes the following remark:

"But as my conclusions have lately been much misrepresented, and it has been stated that I attribute the modification of species exclusively to natural selection, I may be permitted to remark that in the first edition of this work and subsequently, I placed in a most conspicuous position - namely at the close of the Introductionthe following words: 'I am convinced that natural selection has been the main but not the exclusive means of modification'. This has been of no avail. Great is the 
power of steady misrepresentation." (Darwin, 1872: 421, cited in Lawson, 2003: 112)

Nishibe shares this broad view of evolutionary economics, and also criticizes the reduction of evolutionary economics to natural selection, arguing that "evolutionary economics should, without importing evolutionary concepts and ideas directly from biology, identify replicators and interactors unique to socioeconomic domains" (Nishibe, 2006: 20). This is what Lawson does in his PVRS model, when identifying social practices as interactors, and social rules as replicators. Hence, it seems that on a closer view, we find more agreement than disagreement between Nishibe and Lawson.

Furthermore, Lawson notes that even natural selection models can be usefully applied in economics, albeit only when the natural selection analogy (between the biological and social realm) holds, and not universally. Natural selection models provide a more specific instance of the transformational conception of social activity, and hence can be most useful whenever addressing cases where a more specific model is required, whenever the natural selection analogy holds. This is so because natural selection models (such as the PVRS model), and the transformational conception of social activity Lawson endorses, work at different levels of abstraction.

The transformational conception of social activity provides a broad explanation of social activity, general enough in order to accommodate various forms of social phenomena. However, such a broad conception is too general to provide concrete insight concerning more specific phenomena. This is why the analysis of more concrete phenomena requires a more concrete model.

Of course, a more concrete model requires additional empirical claims regarding the nature of the phenomena to be analyzed. In this sense, a more concrete model will be applicable to a smaller number of situations than the transformational conception of social activity, but whenever it is appropriate for analyzing a given situation, it can provide additional insight concerning the more specific features of the phenomena under scrutiny.

When comparing the PVRS model with the transformational conception of social activity in the text cited by Nishibe, Lawson (2003a: 131) notes that "[a] fuller story (at the relevant level of abstraction) is provided precisely by the realist transformational model of social activity". But the qualification "at the relevant level of abstraction" signifies that "fuller story" is meant to denote a more general or abstract story, without entailing that more concrete models cannot provide additional insight. Thus Lawson 
(2003a: 132) writes also: "I am not suggesting the PVRS model cannot have relevance in the social domain; indeed I have suggested some likely applications above", and in fact makes extensive use of the PVRS model in order to explain the mathematising tendency in mainstream economics.

So it seems that the differences between Lawson's and Nishibe's position are not substantial - both share a broad view of evolutionary economics, where the latter is not reducible to natural selection, although natural selection models may be most useful whenever appropriate.

\section{Lamarckian Processes}

A Darwinian natural selection model posits a distinction between the environment of selection-constituted by the competing social practices-and the other aspects of human behavior that may generate some variety of codes, rules, routines and techniques. Now, even though some distinction between selection mechanisms and varietygenerating mechanisms is necessary for Darwinian analysis, it is also the case that these mechanisms may be to some extent interdependent.

In what Lawson (2003a) calls a strictly Darwinian process, the variety generating mechanism is regarded as independent from the selection mechanism. So human dispositions, psychological preferences, habits of thought, and any feature that may influence the replication and variety of social rules, are independent from the environment of selection-i.e., the competing social practices-in a strictly Darwinian model. When the environment of selection has some sort of causal influence on the variety generating mechanism, Lawson names the evolutionary process as a Lamarckian one.

Another important case Lawson discusses takes place when human agents deliberately change the environment of selection. A crucial question then is the extent to which human agents just reproduce structures, or use their capabilities to transform them. The tendencies, dispositions and propensities that social structures and technology set into motion can contribute to their reproduction or even to their transformation. When tendencies contribute mainly to the reproduction of such social and technological structures, their transformation will be possible only if human agents have the capability to act contrarily to those tendencies.

That is, the capability to act contrarily to the tendencies that are set into motion by social and technological structures must be one of the capabilities that the latter enable. Otherwise, the existent social and technological structures will become 'locked in'- to 
use an expression David (1985) employed in the analysis of technology. So for transformation (or modification) to occur, choice must be a real possibility, as Lawson (2003a) also notes.

But in addition to the possibility of choosing, human agents must also have the ability to perceive a given social structure or a given technology as a constraint to their wellbeing and advantage, for the transformation of social or technological structures to occur through a deliberate choice of human agents. And it may happen that social and technological structures are not perceived as constituting a constraint to well-being and advantage.

For example, the daily repetition of social rules and techniques within a given environment will lead human agents to be disposed, or have a tendency, to act according to these (habitual) routinized procedures. In fact, supporters of either the hypothesis that social structures determine human action, or that technology is the ultimate cause of events, make their point by noting how the agents' dispositions, propensities and habits are formed in everyday activity, and thus shaped by the social or technological structures that condition human activity. This causal force is undeniable, and the question is not its existence, but the extent of its influence.

Following given social rules and the repeated use of a given technology often endows the human agent with what Giddens (1984), following Laing (1965), names as "ontological security", that is, the sense of inner security that is provided by sameness and continuity in daily routines and activities — see also Lawson (1997: 180-184). When planning their activity, human agents expect their surrounding environment to remain relatively stable.

The continuous engagement in familiar routines and the temporal endurance of familiar objects gives the agent a sense of psychological security and trust in the external environment. Even the agent's attempt to differentiate and distinguish herself or himself from other human agents can be seen as an attempt to ensure the maintenance of a familiar structure of differences, or an effort to preserve her or his own identity, and her or his conception of herself or himself as a distinct entity.

Such sense of inner security will often lead to a tendency to reproduce the existing social and technological structures, regardless of whether such structures really promote human well-being and advantage. For the daily routines and activities that are reproduced through such structures will be perceived as being essential to human wellbeing, regardless of whether they really are the best promoters of well-being. The tendencies and dispositions to reproduce (rather than to transform) the existent social and 
technological structures will be particularly strong in such cases, and a process of direct selection will reinforce the reproduction of existing structures.

So for transformation or modification to be possible, either the tendencies triggered by social processes must lead to the transformation of its underlying structures (and be stronger than other countervailing tendencies that may contribute to the reproduction of underlying structures), or the capability to act contrarily to tendencies for reproduction must be one of the capabilities that the existent social and technological structures enable. Such capability is closely associated with our ability to perceive and analyze events, and engage in deliberate processes of decision-making through which existent knowledge is transformed.

In fact, the epistemological conceptions we have can also be seen under a transformational or evolutionary perspective: the production of knowledge draws upon previous knowledge, and hence knowledge is a produced means of production, subject to evolutionary processes of descent with modification. The evolutionary analysis suggested above is applied to codes in general, and these include social rules, techniques, and ideas or epistemological conceptions. Nishibe (2006: 10-12) also notes this point, arguing that both economics (as a set of ideas and theories) and the economy stand in a recursive relation, in which both co-evolve as complex systems.

So the question of whether evolution is a deterministic process or not, depends on the range of capabilities that are left to the human agent. Whenever social and technological structures shape human tendencies, propensities and dispositions in a way that strongly limits the scope of human capabilities, evolution will be constrained to proceed in a particular direction. But such a situation happens only in particular cases. Whenever human capabilities are sufficiently broad, human agents will be able to choose amongst different courses of action, provided their intentionality and propensity for action is not totally determined by social and technological structures, and various evolutionary sequences will then be possible.

In the transformational conception suggested here, agents are influenced, but not totally shaped by, technology and social structures. The causal influence of technology and social structures on human agents can be conceptualized as a particular case within a general evolutionary model, a particular case which was designated here as a Lamarckian process, wherein the environment of selection has some influence on the mechanisms through which variety and replication occur, i.e., it changes the dispositions and propensities to create or maintain rules. The deterministic case is just an extreme situation within this particular case. 
Either in the evolutionary model presented or in a deterministic account of social activity, biological, social and technological structures influence outcomes not only by providing the conditions of possibility for action, but also by, to some extent, transforming the (dispositions and propensities of the) agent. But deterministic conceptions of social activity would argue that events and agents are entirely shaped by technology or social structures, in what could be conceived as a (Lamarckian) model where selection mechanisms completely determine replication mechanisms and varietygenerating mechanisms.

\section{Identifying Social Replicators}

A key question for the practical application of the PVRS model suggested above is the identification of the specific social replicators that have been selected throughout socioeconomic history, in each specific environment. This, in turn, requires further empirical claims concerning concrete historical events, so that the evolutionary model suggested above can be applied.

Veblen (1898b, 1899) noted how the struggle for survival in a difficult natural environment would lead to the need of group solidarity and to an active propensity towards the search of nutrition and protection. Such were the conditions until the last Ice Age, and these conditions shaped the instincts and habits of thought (and so the social replicators) of Veblen's 'savage society'. The term "savage society" springs from the distinction between 'savagery', 'barbarism' and 'civilization' Veblen used, and had been suggested before by Morgan (1877).

The development of tools that enable a larger production of goods (including the production of a surplus), and of tools that made predacious activities more efficacious or destructive, led to a change in the environment, which promoted invidious comparisons and competition between groups, and between individuals within the group. This leads to Veblen's 'barbarian society', where invidious comparisons brought the development of a system of authoritarian relationships.

At a later stage, in many places in Western Europe, the institutional struggles between monarchs and feudal lords (during which monarchs tended to promote the development of cities and markets in order to weaken the economy of each feudal domain and hence the feudal lords' power), together with the technological innovations in transportation, which enabled moving goods through longer distances, promoted the formation of markets. Markets, in turn, required that land, labor and capital be exchangeable, and contributed to the development of an abstract system of rules of exchange, which 
progressively substituted the feudal system of authoritarian and personalized relations (which, for Veblen, was just a more advanced stage of the 'barbarian society', since the vassalage system is just an elaborated system of authoritarian relationships similar to those developed in the 'barbarian society').

This led to the formation of what we may term as the "competitive system" (Veblen 1914: 187), or 'commercial society', in which social relations follow an abstract system of rules that are applicable to every individual—for the efficiency of the market requires that its rules can be applied to any individual or good, and collides with the feudal system where land, labor and capital are governed by a complex system of authoritarian and personalized relations. Finally, the emergence of the technology of mass production- "machine industry", to use Veblen's (1914: 299) words-gives us a type of society we may term as the 'industrial society', in which social activity is governed by the discipline of the machine process, for it is the machine logic that sets the pace of human activity.

Of course, like any evolutionary process, the above is a process of cumulative causation, in which every society maintains characteristics of a previous society-Veblen gives the example of how the high level of consumption of expensive goods observed during the stage of "machine industry" exists because individuals often consume for an invidious motive, that is, the conspicuous consumption of expensive goods is a 'barbarian' symbol of superiority. Also, Veblen (1904) characterizes the period termed here as 'commercial society' as a hybrid period, in which traces of the previous stages (viz., the 'savage' and the 'barbarian' society) still exist. Veblen is not alone in this interpretation of the 'competitive' or 'commercial' stage as a hybrid situation. Schumpeter (1942) also argued later how capitalism exists in a relation of symbiosis with feudalism, and John Stuart Mill's (1848) analysis of the transition from a society structured by 'custom' to a society structured through 'competition' also implies the coexistence of custom and competition in a transition stage.

Hence, the contemporary society comprises a variety of social rules (grounded in different principles like solidarity, authority, abstract laws and technological requirements) which were developed in specific selection environments, in a (evolutionary) process of cumulative causation. Each of these social rules will be present in corresponding social practices to a greater or lesser degree, depending on the selection environment.

It is also important to note that there are interesting relationships between Veblen's typology, and other typologies that appeared later in the literature. Polanyi (1944), for 
example, distinguishes between different modes of distribution of goods, like reciprocity (the mutual exchange of goods as part of a long-term relationship), redistribution (which requires the existence of a central entity or figure, to which all goods are directed, and who then distributes them to the community) and (market) exchange (the exchange of goods through a market mechanism, i.e., according to a price system).

Now, Polanyi's reciprocity seems to be the key coordination mechanism at play in Veblen's 'savage' society, in which group solidarity is crucial for survival. Redistribution by a central authority would be the key coordination mechanism at play in a 'barbarian' society, and market exchange would be the coordination mechanism in the 'competitive' or 'commercial' society.

These distinctions also share some resemblances to Heilbroner's (1993) distinction between tradition (comprising a rigid structure of norms, like those that characterize societies based on reciprocity), command (the coordination mechanism in authoritarian societies) and market (a decentralized coordination mechanism) as modes of production and distribution, although some differences remain (for example, tradition need not mean reciprocity).

So we can distinguish between: coordination mechanisms based upon a set of traditional rules of reciprocity like those of Veblen's 'savage society'; coordination mechanisms based upon authoritarian relations of command like those of Veblen's 'barbarian society'; decentralized mechanisms like the market exchange mechanism of the 'competitive system', i.e. the 'commercial society', and the coordination mechanisms during 'machine industry', which depend upon the machine process.

One can now combine this analysis with Lawson's PVRS model explained above, and conceptualize the social replicators as the set of social rules that underlie the coordination mechanisms used in any organization or regional community, in an evolutionary model of socio-economic transformation where individuals, organizations and regions compete through the actualization of rules and codes (including techniques) as social practices.

The most competitive entities will be those which have social replicators that enable a better adaptation to the environment of selection. For example, decentralized coordination mechanisms like the market will be more efficient when there is a large amount of decentralized information to be managed — as Hayek (1948, 1988), who spent much time analyzing evolutionary processes, and like Lawson suggested the use of social rules as social replicators, also noted-but centralized mechanisms of command will be more efficient whenever a centralized coordination of various resources is required. 


\section{Evolutionary Analysis and the Causal Efficacy of Social Structures, Technology and Human Agency: Some Illustrations of Why Evolution is a Non-deterministic (Transformational) Process}

The distinction between variety-generating mechanisms, replication mechanisms and selection mechanisms, made in the context of an evolutionary model of socio-economic transformation, together with an understanding of the specific social replicators identified in the previous section, can illuminate some disputes in the literature on social structures, technology and agency, like the question of whether social structures or technology are the ultimate determinant of history. The PVRS model described above enables us to conceptualize the causal efficacy of social and technological structures, while taking into account the irreducibility of the causal powers of human agents, within a broad transformational conception-thus avoiding deterministic interpretations of history.

Under the PVRS model specified above, the disposition and propensity of the agent to create new codes, rules, techniques and ideas can be conceptualized as a varietygenerating mechanism. The causal force of existing social and technological structures can be seen as part of the selection environment, for social practices are the actualization of the codes, rules, techniques and ideas that constitute social and technical structures. Whether social and technological structures determine human agency or not will depend on how strong is the pressure of the environment of social practices, and whether it leaves the agent with more or less possibilities.

As noted before, technology has often been regarded as the ultimate determinant of events in economic history, in a perspective often referred to as "technological determinism". Veblen was a particularly influential author in emphasizing the role of technology in the transformation of society. However, a question that can be asked is whether technology really is the only driving force behind historical transformation (even in Veblen's conception).

Previous perspectives on the work of Veblen have taken into account the joint effects of technology and institutions, while nevertheless still attributing the cause of change to technology alone. Ayres $(1944,1952)$, for example, argued that technology is the dynamic force of change in economic activity, while institutions are a static force that constrains change. This understanding of technology and institutions is often referred to as the "Veblenian dichotomy", because it has been interpreted in the literature as representing Veblen's position—on this see, for example, Hamilton (1953).

The "Veblenian dichotomy" captures the insight that change is often brought through technological innovation, but it must be interpreted with caution. In fact, not only is the 
existence of given technologies often a constraint to change-for example, when technologies become 'locked in', on which see David (1985)—as it may happen that change is promoted by the institutional context, or even driven by institutional struggles, as will be discussed later.

Under the light of the PVRS model described above, the causal role of technology can be conceptualized in a non-deterministic way. The invention of new technologies can be seen as a variety-generating mechanism. In this perspective, technology is not the only determinant of history because the success of technological innovations depends on the environment of selection in which new techniques are implemented.

For example, the technological innovations in transportation which enabled the transportation of goods through long distances, thus facilitating the expansion of the market system, would not be widely implemented if there were not a social environment supported by corresponding institutions (and, of course, by other technologies as well), including the coordination mechanisms that could manage such enterprises. Coordination mechanisms based on tradition could not accommodate the enormous amount of new information to be managed concerning the new varieties of products from different places. The need to manage new information required market exchange as a coordination mechanism.

It is true, nevertheless, that technological innovations in transportation also promoted the expansion of the market as the key coordinating mechanism throughout the world economy - an expansion Polanyi (1944) believes to be the key characteristic of the modern era, and the cause of the destruction of economies based on reciprocity — which has been conjoined with the existence of centralized command mechanisms, like the political and military command mechanisms of nation-states (or, one could add, the centralized economic mechanisms often used today by large private companies and corporations).

However, the expansion of the market and command as coordination mechanisms, replacing reciprocity and tradition, and of the technologies that enabled transportation of goods through long distances, was a co-evolution in which institutional coordination mechanisms and technology mutually reinforced each other, and not a deterministic process driven by technology alone, as suggested in some extreme interpretations of the "Veblenian dichotomy".

In fact, it can be argued that institutional conflicts were the key element in the generation of an environment that favored the market over the feudal economic systems. Before the changes in transport technology named above, markets already existed, and 
their development depended essentially upon institutional power struggles. As Smith (1776) notes, the monarchs' support to the expansion of cities, and the development of commercial activities in cities that were outside of the feudal system, helped kings to centralize their power, by reducing the economic influence and power of feudal lords.

Between the power struggle opposing monarchs and feudal lords, cities outside the domain of the feudal lords, and a wide variety of commercial activities within such cities, coordinated through market mechanisms, found a favorable environment for their development. So changes in transport technology only facilitated the selection of an already existent coordination mechanism - the market, which was already developing within cities - as the coordination mechanism that articulates relationships between different locations in the world economy.

As cities became more important, the power of feudal lords declined relatively to the power of kings, and centralized monarchies gained control over an increasingly centralized national economy that contrasted with the relatively decentralized feudal world. The reinforcement of the asymmetrical power relations of the centralized monarchies over feudal lords created a new balance of power, and a national economy of cities replaced decentralized feudal systems, becoming the new environment of selection. Such a new environment of selection was constituted by a world economy where nationstates, which were geographical regions with a centralized and independent political organization, became central institutional forces.

This was a major institutional change that was not directly caused by technological change alone, and in fact can be better understood when taking into account the evolutionary pressure exercised by the environment of selection. It led to a change from an authoritarian system of devolution to a system based on economic competition, which in turn required a new institutional setting. Feudal society provided an environment where authoritarian relations were relatively more efficient due to the need of protection, as John Stuart Mill (1848) notes. The market, in turn, created an environment that favors competitive relations, and requires the specification of an abstract set of rules that are equally applicable to all agents regardless of their status - on this, see also Veblen (1904).

In this new environment of selection, centralized monarchies became increasingly important buyers for economic goods related to national activities (armadas, armies, palaces and related industries, for example), providing new markets for economic activity. A well-known example of the influence of this new environment of selection is the French national demand for tapestry, or the Flemish demand for textiles discussed by 
Marx (1867), which led to the redirection of economic activity of suppliers of wool (such as those in England) to its production, leading in turn to the expropriation of land, to be used in pasture to produce wool, and to the enclosure of private properties which before were common lands. The increasing difficulties in finding new lands for agricultural activity, together with the belief that private ownership provided a stronger incentive towards productivity (which reflects the influence of the expanding commercial habits of thought) further contributed to the enclosure of agricultural property.

This change of the selection environment, in turn, caused a great decline in the wellbeing of many agricultural laborers. In the feudal system, most of the product of work in common lands (unlike the product of work in the lords' lands) was kept for the laborersee Cameron (1993). Without the possibility of working in common lands, agricultural workers who did not possess lands had fewer prospects of keeping a share of their work in order to earn an income above the subsistence level, and became willing to move into cities if they had the opportunity to find better prospects there.

The variety of new technologies that emerged with the industrial revolution was also much favored by this environment of selection where a large labor force was willing to leave lands in which the benefits of agricultural work were decreasing. So even the technological innovations of the British industrial revolution benefited from a favorable environment for their implementation, rather than imposing their logic regardless of the surrounding environment.

The technological innovations that led to the appearance of factories and mass production in urban centers not only benefited from the availability of the labor force mentioned above, as they generated again a new environment of selection where urban centers have a competitive advantage over rural areas and traditional modes of production.

Furthermore, mass production required not only an increasingly larger number of workers, but also an increasingly larger number of buyers, and the selection environment provided by mass production made larger cities even more competitive due to their high population density, and the demand it provides for output. Of course, one town cannot constitute a sufficiently large market for mass production, and therefore the technological innovations that led to mass production would not have been successful outside of an environment of selection where new technologies of transportation (which once installed came to support the new selection environment), combined with market mechanisms, allowed goods to reach a large number of consumers across several cities, and relied also on the emergence of institutions like decentralized smaller companies (and, later, the 
modern large corporations), which in turn depended upon coordination mechanisms that were sufficiently flexible to new information.

Not only was this institutional setting essential to socio-economic transformation, as it is also the case that the technology of mass production has since then become a force that maintains the competitive advantage of urban centers above rural areas, rather than a cause of change in such a state of affairs. This, again, reinforces the point that institutions and technology co-evolve in a process where both can be inducers, or inhibitors, of socio-economic change.

The contemporary increase in the amount of new information to be managed ultimately led to the emergence of the market as the most important coordination mechanism in distribution. This does not mean that asymmetrical power relations do not exist in the market, for market competition is often imperfect competition (for example, when some companies have higher control over components of the selection environment, such as prices). Also, nation-states, and their centralized mechanisms of political decision, still play a key role in economic relations. This political and institutional framework governed both by market mechanisms and command mechanisms is, like technology, essential to evolutionary processes of variety-generation, replication and selection.

The point to note is that this brief historical digression contains episodes where both institutions and technology contributed to selection, and where both institutions and technology generated variety, or replication. So it seems difficult to attribute only one of these roles to each of the terms of the so-called Veblenian dichotomy. Ayres' position seems to focus on a particular aspect of this co-evolution, which captures the fact that variety is often introduced through technological change, but its selection faces the institutional forces that are continuously replicated and actualized in the environment.

However, the conception of technology as the ultimate determinant of change is difficult to sustain when scrutinizing the latest transformations throughout economic history, because change was often introduced by institutional struggles - and, moreover, technological innovations were selected only when they found a favorable environment. A broad transformational conception, within which evolutionary processes often play a crucial role, seems to provide a better explanation of these historical events.

In short, both institutions and technology can act either as forces of change or against change, because both can act as variety-generating mechanisms, replication mechanisms or selection mechanisms. It need not be the case that technology is the only cause of change, or that institutions are everywhere static. Not only can institutions provide 
variety, as it is also the case that once technology becomes a part of the environment, it often acts as a force of stasis and maintenance of the current state of affairs, and not as a force of change. This is certainly the case when technologies become 'locked in'-for another critique of the way in which the Veblenian dichotomy is often portrayed, see Lawson (2003b, 2005), who attributes the formulation of the dichotomy to the insufficient ontological grounding of the notions of agent and social structure as distinct entities, and argues that the dichotomy just reflects a particular instance of the concern with forces driving stability and change that characterizes "old" institutional economics.

\section{Evolutionary Analysis and the Transformation of Human Agents and Epistemological Conceptions: Some Further Illustrations of Why Evolution is a Non-deterministic (Transformational) Process}

It is not just institutions and technology that are transformed throughout economic activity, but also the human agent. In fact, a possible justification for deterministic conceptions is that technology or institutions determine events by shaping the habits and dispositions of human agents, as noted before.

As mentioned above, Veblen $(1898 \mathrm{~b}, 1899)$ argued that the environment of selection shapes the human individual, and that the need of group solidarity that characterized earlier communities was a necessary requirement for the survival of the group. As human beings became able to produce a larger amount of goods, the environment of selection changed, for the existence of a surplus promoted the tendency towards invidious comparisons and competition between groups, and between individuals within the group.

These two tendencies of human agents (for group solidarity and for individual competition within a group, respectively) continue, of course, to exist, and tend to become more or less prominent depending on the environment of selection. Evolutionary selected entities like markets, large companies and large urban areas provide an environment of selection that conditions the development of these human propensities, and of the corresponding social replicators.

Market relations involve the careful calculation of gains and losses. As more people engaged in market relations and in the corresponding calculation of gains and losses, the latter attitude became widespread across increasing segments of the population, who once accustomed to this instrumental, rationalistic and individualistic mentality began to use it to assess not only economic institutions (the change of attitude towards guilds is an example), but other social institutions as well, as Schumpeter (1942) notes. This instrumental approach is present today in philosophical perspectives like utilitarianism, 
and is presupposed in the neoclassical economic models of choice and behavior-a wellknown alternative evolutionary analysis of the tendency towards instrumental pursuit of individual well-being is provided by Dawkins (1976).

Social replicators, like the individualistic and rationalistic attitudes named above, found a favorable selection environment in the market system, which enabled the fulfillment of economic needs without belonging to a social network of reciprocal relations (like those of Veblen's "savage society") or authoritarian relations (for example those of Veblen's "barbarian society"). Economic security, which before was assured by belonging to a network of (reciprocal or authoritarian) social relations, now depends increasingly on the rational engagement with the market system. This absence of a need of belonging to long-term social networks to fulfill economic needs, combined with the expansion of an urban environment, again contributed to the development of individualistic and rationalistic attitudes.

Furthermore, there seems to be a Lamarckian process at play as well, for the environment of the market system, together with what Veblen (1904) designated as the "machine process" imposed by technology, shapes habits of thought towards the rational and instrumental pursuit of individual well-being. The pre-industrial mode of production was dependent on uncertain weather conditions, and made unpredictability a constant factor in human life. The post-industrial mode of production relies on technologies that are not dependent on such uncertain factors, while both promoting the expansion of rationalistic attitudes and shaping habits of thought in the same direction, by promoting the standardized logic of the machine.

So the fact that the market mechanism is the key means of distribution is not the only factor contributing to the expansion of rationalistic attitudes. The change in the mode of production also contributed to this process. The shift towards habits of thought that privilege instrumental calculation of gains and losses, facilitated by the selection environment of market relations, and combined with a Lamarckian process of change of human dispositions, accelerated the destruction of the traditional and reciprocal relations that characterized pre-industrial societies. In this sense, technology acted first as a promoter of change by generating a new variety of attitudes, but is now a force acting against change through its contribution towards the maintenance of rationalistic and individualistic attitudes.

These individualistic attitudes (motivated by instrumental rationality) generate a new environment that poses new challenges, due to the tendencies towards the production and consumption of private goods that they generate. Market mechanisms based on 
individual self-interest tend to bring about a lack of balance between public and private goods (the market privileges the production of private goods), and also a lack of balance between investment in material resources and human resources (the market privileges investment in the former), as Galbraith (1958) notes. The command mechanisms of the centralized nation states that were left as an offspring of centralized monarchies are increasingly unable to produce an amount of public goods and investment in human resources that successfully balances the market production of private goods and market investment in private resources.

But can it be said that individualistic and rationalistic attitudes, as an increasingly predominant social replicator, are being brought through a deterministic process, caused by the influence of technology, or the market system, upon the human agent? Again, there seems to be enough historical evidence to refute the claim that deterministic processes are brought about through changes caused in the dispositions of human agents. In fact, similar environments to the ones that led to the development of individualistic attitudes, also led to reciprocal, as opposed to individualistic, social relations, through solidarity networks, either promoted by religious groups, public or private institutions, civil society organizations, or even commercial companies.

Take, for example, the cooperative movements of the $19^{\text {th }}$ century. The industrial revolution led to the bankruptcy of many smaller companies throughout the $19^{\text {th }}$ century. This led many workers to lose their job due to a change in the mode of production and organization, and created an environment of selection in which workers could either join the new industries, or create other companies that could compete in such a new environment.

While many workers chose to take part in the new emerging mode of production, other workers decided to create alternative organizations with different modes of organization. The need of incorporating new information about a new and rapidly changing environment led selection mechanisms to favor more innovative organizations, with variety-generating mechanisms creative enough. This creative potential was found in organizations with coordination mechanisms based on reciprocity, such as those instituted in cooperative movements like Rochdale-where all agents were owners with similar property rights, and with a more participatory method of decision-making, enabling the inclusion of a greater amount of information in its collective decision processes.

Here, what was termed above as a direct selection mechanism was at play, for it was the pressure of the environment (including social structures, technology and the mode of 
production) that led workers to develop coordination mechanisms based on reciprocity. However, there was not a single causal factor determining historical events (either through its influence upon human agents or through other means), but rather an environment of selection constituted by a complex set of forces, which in turn provided a set of capabilities for human agents.

The causal influence of social structures, technology or the mode of production is, of course, recognized, and conceptualized here through their effects in the environment of selection, which promoted the emergence of cooperatives. In fact, as John Stuart Mill (1848) documents, as soon as cooperative movements like Rochdale become successful enough to soften the pressure of the competitive selection environment over the cooperatives, the cooperative's members started to include members that did not have any right to property, and whose activity was coordinated through command.

That is, the change in the environment led to a change in the process of direct selection of social practices, so that individual members were no longer pressured towards reciprocal relations and practices by external competition, and thus chose to establish asymmetrical relations of power with new members of their organization. Note again how it is the pressure exercised by the environment of selection upon the group that first promoted the development of group solidarity in cooperatives, as in the case of the primitive (savage) communities analyzed by Veblen (1898b, 1899), and how it is again the reduction of such pressure that encourages the abandonment of the original group solidarity in cooperatives (through what was defined above as a process of direct selection). The causal role of the socio-technological configuration that shapes the environment of selection is thus central to this process.

But the point to note is that various types of organizations, structured either through cooperative or non-cooperative social relations, co-existed as a response to a changing environment, and there was never a single causal factor (be it technology, social structures, or the mode of production) determining socio-economic activity in a particular direction, but rather a set of causal factors shaping a given environment of selection, which in turn facilitated or constrained particular courses of action. Rarely (if ever) the space of human capabilities becomes sufficiently restricted by institutions or technology so that deterministic processes occur.

As noted before, cases where institutions or technology completely determine human action can be seen as particular cases, for example when human capabilities become restricted enough so that a given choice is imposed, or when, in an exclusively Lamarckian process, the environment of selection determines human dispositions. In 
general, social processes can be best characterized through a transformational (nondeterministic) conception, where natural selection models provide a more specific account of particular mechanisms at play (including variety generating, replication and selection mechanisms).

\section{Concluding Remarks}

An evolutionary model built upon a broad transformational conception seems thus to provide the basis for a non-deterministic account of socio-economic change. The social rules and codes present in contemporary economic activities, and the individuals, organizations and regions that engage in them, can be seen as the outcome of a nondeterministic (transformational) evolutionary process. In distribution activities, the market is today the key coordinating mechanism, albeit market power varies greatly between organizations and regions.

Of course, replicators associated to other coordination mechanisms like tradition, reciprocity and command still exist. The personal advantages that spring from the exertion of asymmetric power (developed to a high degree in feudal society), combined with an individualistic and rationalistic attitude that emerged in the competitive system, underpin asymmetrical relations as an important code (or social replicator) in production activities within many organizations today. Tradition and reciprocity play however an important part is shaping the social and cultural potential of many organizations too.

The geographical morphology of regions was also radically changed, with the selection environment being more favorable to the development of large urban centers (that function according to the evolutionary selected codes), which continue to gain prominence against rural areas.

Causal forces like social structures, technology, human agents and the mode of production, were each identified by different intellectual traditions as being the ultimate cause of events. In the evolutionary model suggested here, all such causal forces can be incorporated under a broader transformational perspective. It may be that at a particular historico-geographical configuration, some of these forces are more important than others, but such a possibility can be incorporated as a particular case within the perspective suggested here.

The forces that act towards the reproduction of codes, social rules, techniques and ideas are replication mechanisms, while the causal powers that contribute to the transformation of codes, social rules, techniques and ideas are variety-generating mechanisms. But in order for social replicators to be actualized as social practices, each 
variety of codes, social rules, techniques and ideas, that are continuously generated and replicated, must be selected within an environment constituted by the totality of codes, social rules, techniques and ideas that technology, social structures and human agents generate and reproduce throughout human practices.

The social structure, like technology and the mode of production, arises through human agency, but it is not reducible to the interaction of human agents from which it first emerged. Human agents take this structure as given at each moment they act, while reproducing and/or transforming such structure in their daily activity. Therefore, rules, custom, ideas, techniques, beliefs, norms and conventions are to be understood as constituents of social reality, that are reproduced through human agency, but do not completely determine the latter, so they can also be transformed by human agency.

The institutions of each historical period described here were a strong force in shaping human habits and action. But this process need not entail that individuals will necessarily see their capabilities reduced in a way that completely determines their course of action. It may be that as social and technological structures develop, shaping the conditions of possibility for human agency, they end up leaving very few options for agents to choose from.

Furthermore, social structures and technology are very important in shaping the personality and identity of the individual who slots into a given social position within such a structure. But if agents are ontologically distinct entities, as the transformational conception of social activity suggests, they have the possibility of attempting to change, or indeed change, modes of production, institutions, identities, affiliations and social positions, through the exercise of reasoning and reflexivity.

In the evolutionary model suggested above, the causal influence of social structures and technology upon the dispositions and propensities of human agents can be conceptualized as a Lamarckian process, wherein the environment of selection changes the mechanisms through which variety and replication occur, i.e., changes the dispositions and propensities to create or maintain rules. But even in this case agents can be seen as being influenced, but not totally shaped, by technology and social structures.

The advantage of the transformational conception suggested above is that it provides a general outline of the causal mechanisms of socio-economic transformation, while being able to encompass several particular cases in its more general framework. Deterministic accounts often provide an insightful description of one of the causal mechanisms at play (technology, social structures, mode of production or human agency), but take only one of the possible causal factors into consideration. 
All this signifies that the PVRS model presented above, like evolutionary analysis in general, is not incompatible with the transformational conception of social activity Lawson endorses. Quite the contrary, the PVRS model and the transformational conception of social activity are complementary and mutually enriching, since they work at different levels of abstraction: the PVRS model can be seen as a more specific instance of the transformational conception of social activity.

Also, the fact that the transformational conception of social activity and the PVRS model provide non-deterministic explanations of historical events means that historical analysis must always be supplemented with empirical analysis of each concrete event. Since historical events are not totally determined by underlying structures, forces or laws, the study of general structures will not be sufficient to provide a complete account of concrete historical events.

\section{References}

Ayres, C. (1944) The Theory of Economic Progress, 1st ed., University of North Carolina Press, Chapel Hill, N.C.

- (1952) The Industrial Economy: Its Technological Basis and Institutional Basis, Cambridge, Mass., Houghton Mifflin.

Cameron, R. (1993) A Concise Economic History of the World: from Paleolithic times to the present, Oxford, Oxford University Press.

Collier, A. (1989) Scientific Realism and Socialist Thought, Hemel Hemsptead, Harvester Wheatsheaf.

Cook, S. (2009) The Intellectual Foundations of Alfred Marshall's Economic Science: A Rounded Globe of Knowledge, Cambridge University Press, Cambridge.

Darwin, C. (1859) On the Origin of Species by Means of Natural Selection, or the Preservation of Favoured Races in the Struggle for Life, 1st ed., John Murray, London.

David, P. (1985) "Clio and the economics of QWERTY," American Economic Review (papers and proceedings), 75: 332-337.

Dawkins, R. (1976) The Selfish Gene, Oxford University Press, Oxford.

(1978) "Replicator Selection and the Extended Phenotype," Zeitschrift für Tierpsychologie 47: 61-76.

Galbraith, J. K. (1958) The Affluent Society, Houghton Mifflin, New York.

Giddens, A. (1984) The Constitution of Society, Polity Press, Cambridge.

Graça Moura, M. da (2002) "Metatheory as the Key to Understanding: Schumpeter after Shionoya," Cambridge Journal of Economics 26: 805-821.

Hamilton, D. (1991 [1953]) Evolutionary Economics: A Study of Change in Economic Thought, 
Transaction Publishers, New Brunswick, N.J.

Hayek, F. A. (1948) Individualism and Economic Order, Chicago University Press, Chicago and London.

(1988) The Fatal Conceit: The Errors of Socialism. The Collected Works of Friedrich August Hayek, Vol. I, William W. Bartley III (ed) Routledge, London.

Hegel, G. W. F. (1953 [1824a]) Reason in History: A General Introduction to the Philosophy of History, Liberal Arts Press, New York.

_ (1956 [1824b]) The Philosophy of History, Dover Publications, New York.

Heilbroner, R. L. (1967) “Do Machines Make History?” Technology and Culture 8: 335-345. (1993) 21st Century Capitalism, Norton \& Company. New York, W. W.

Hull, D. (1981) "Units of Evolution: A Metaphysical Essay”, in U.J. Jensen and R. Harré (eds) The Philosophy of Evolution, Harvester Press, Brighton, pp. 23-44.

Laing, R. D. (1965) The Divided Self, Hammondsworth, Penguin.

Lawson, C. (2007) "Technology, Technological Determinism and the Transformational Model of Social Activity" in C. Lawson, J. S. Latsis and N. Martins (eds) Contributions to Social Ontology, Routledge, London.

- (1997) Economics and Reality, Routledge, London.

- (2003a) Reorienting Economics, Routledge, London.

(2003b) "Institutionalism: on the need to firm up notions of social structure and the human subject," Journal of Economic Issues 37: 175-201.

- (2005) "The Nature of Institutional Economics," Evolutionary and Institutional Economics Review 2: 7-20.

Marshall, A. (1890) Principles of Economics, Macmillan and Co., London.

Marx, K. (1999 [1867]) Capital, Oxford University Press, Oxford.

Mill, J. S. (1848) Principles of Political Economy, J. P. Parker, London.

Morgan, L. H. (1877) Ancient Society, Henry Colt and Co., New York.

Nelson, R. R. (2006) “Evolutionary Social Science and Universal Darwinism," Journal of Evolutionary Economics 15: 491-510.

- (2007) "Comment on: Dismantling Lamarckism: Why Descriptions of Socio-Economic Evolution as Lamarckian are Misleading, by Hodgson and Knudsen," Journal of Evolutionary Economics 17: 349-352.

- and S. Winter (1982) An Evolutionary Theory of Economic Change, Belknap Press, Cambridge MA.

Nishibe, M. (2006) "Redefining Evolutionary Economics", Evolutionary and Institutional Economics Review 3: 3-25.

Polanyi, K. (1944) The Great Transformation: The Political and Economic Origins of Our Time, Boston, Beacon Press.

Pratten, S. (1998) "Marshall on Tendencies, Equilibrium and the Statical Method," History of 
Political Economy 30: 121-163.

Raffaelli, T. (1991) "The Analysis of the Human Mind in the Early Marshallian Manuscripts," Quaderni di Storia dell'Economica Politica 9: 30-58.

Schumpeter, J. (1992 [1942]) Capitalism, Socialism and Democracy, Routledge. London and New York.

Smith, A. (1776) An Inquiry into the Nature and Causes of the Wealth of Nation, Methuen and Co., Ltd. London.

Smith, M, and L. Marx (eds) (1996) Does Technology Drive History? the Dilemma of Technological Determinism, MIT Press.

Veblen, T. (1973 [1897]) "Review of Max Lorenz Die Marxistiche Socialdemokratie”. Reprinted in Essays, Reviews and Reports by Thorstein Veblen, edited with an introduction by Joseph Dorfman.: Augustus Kelley, New York.

- (1898a) "Why is Economics Not an Evolutionary Science?," The Quarterly Journal of Economics 12: 373-397.

(1898b) "The Instinct of Workmanship and the Irksomeness of Labor," The American Journal of Sociology 4: 187-201.

- (1899) The Theory of the Leisure Class, Macmillan, New York. (1904) The Theory of Business Enterprise, Charles Scribner's Sons, New York.

(1914) The Instinct of Workmanship and the State of the Industrial Arts, Macmillan, New York.

Whitaker, J. (ed) (1975) The Early Writings Economic Writings of Alfred Marshall (2 vols.) Macmillan, London. 